\title{
Letter to the Editor: Effective Technique for Pancreas Transplantation by Iliac Vascular Transposition, Without Heparin-Based Anticoagulation Therapy
}

\author{
Eric Siskind ${ }^{1} \cdot$ Jorge Ortiz $^{2}$
}

Accepted: 10 January 2022 / Published online: 2 February 2022

(C) The Author(s) under exclusive licence to Société Internationale de Chirurgie 2022

I read with great interest the October 2021 article entitled "Effective Technique for Pancreas Transplantation by Iliac Vascular Transposition, Without Heparin-Based Anticoagulation Therapy" [1]. While I agree that iliac vein transposition can be an effective method for pancreas transplantation; I was surprised that the discussion stated that it is of benefit to avoid portal venous jump grafts due to the increased risk of thrombosis. The reference quoted was from a 2012 study from Prog Urol, Please see our updated 2014 paper which showed no increased risk of thrombosis with portal venous jump grafts. The use of venous jump grafts in pancreatic transplantation-no dif- ference in patient or allograft outcomes-an update of the UNOS database [2].

\section{References}

1. Kaku K, Okabe Y, Sato Y, Hisadome Y, Mei T, Noguchi H, Nakamura M (2022) Effective technique for pancreas transplantation by iliac vascular transposition, without heparin-based anticoagulation therapy. World J Surg. 46(1):215-222

2. Siskind E, Maloney C, Ashburn S, Akerman M, Siskind T, Goldberg L, Bhaskaran M, Basu A, Molmenti E, Ortiz J (2014) Clin Transplant. 28(8):883-8

Publisher's Note Springer Nature remains neutral with regard to jurisdictional claims in published maps and institutional affiliations.

Eric Siskind

eric.siskind@umcsn.com

1 University Medical Center of Southern Nevada Center for Transplantation, 901 Rancho Lane UMCSN Center for Transplantation, Suite 250, Las Vegas, NV 89106, USA

2 Albany Medical Center, Albany, NY, USA 